\title{
Lived Experience of Thalassaemic Children in Bangladesh
}

\author{
Khaleda Akter'1, Shanzida Khatun², Md. Sazzad Hossain ${ }^{2}$ \\ ${ }^{1}$ Dhaka Nursing College, Dhaka, Bangladesh \\ ${ }^{2}$ Faculty of Child Health Nursing, NIANER, Dhaka, Bangladesh \\ Email: khaledaakter3978@gmail.com
}

How to cite this paper: Akter, K., Khatun, S. and Hossain, M.S. (2020) Lived Experience of Thalassaemic Children in Bangladesh. Open Journal of Nursing, 10, 1109 1125 .

https://doi.org/10.4236/ojn.2020.1011079

Received: July 6, 2020

Accepted: November 24, 2020

Published: November 27, 2020

Copyright (C) 2020 by author(s) and Scientific Research Publishing Inc. This work is licensed under the Creative Commons Attribution International License (CC BY 4.0).

http://creativecommons.org/licenses/by/4.0/

\section{(c) (i) Open Access}

\begin{abstract}
Background: Worldwide thalassemia poses a serious public health problem due to the high prevalence. Globally, 15 million people are suffering from clinically thalassemic disorders. Objective: To describe the lived experience of thalassaemic children in Bangladesh. Methods: This study was conducted following a descriptive qualitative research approach. Twenty thalassemic children were recruited purposively in the present study. Semi-structured individual's interview guidelines were used to collect in depth information. In addition, digital recorder was used to capture the children's voice. Data were analyzed using the process of content analysis. This study was approved by the Institutional Review Board (IRB), NIANER. Results: The mean age of the thalassemic children was (16.05) SD $=1.877$. Most of the children were Mus$\lim (95.0 \%)$ and they study at school (70.0\%). Most of their mothers were (90.0\%) housewife. This study revealed four major themes and eleven subthemes based on the experience of thalassemic children: 1) understanding of children meaning of thalassaemia: perception of children, unable to perform daily activities, and educational impact, 2) feeling frustrating experience and disease management: feelings about long term treatment, coping and altered body image, 3) family relationship: differences from siblings, parental attention and feeling burden, and 4) social interactions: sharing with peer, inability to social interaction. Conclusion: This study indicated that thalassaemia has affected negatively on several areas of health of these children including physical, emotional, social financial and educational areas. Reducing these problems requires comprehensive constant support and surveying health and medical status of these children to promote care and decrease the suffering of thalassaemic children. The findings of the present study are grounds for further research in a wider range to describe the different areas of the experience of thalassaemic children.
\end{abstract}




\section{Keywords}

Lived Experience, Thalassaemia, Children

\section{Introduction}

\subsection{Background}

Thalassaemia is the most common inherited single gene disorder in the world that represents a major public concern. It is characterized by a defect in the gene responsible for production of hemoglobin. It is the most common hereditary anemia in the world with approximately 300 million carriers [1]. Globally, 15 million people are suffering from clinically thalassemic disorders apparently [2]. Worldwide, thalassemia poses a serious public health problem due to the high prevalence [3] [4]. The World Health Organization (WHO) has introduced thalassaemia as the frequently chronic genetic disorder in 60 global countries [5]. Approximately 200,000 patients with major thalassaemia have been reported in the world and each year about 60 thousand people will add to this figure [6]. Thalassaemia influence 100,000 children's activity around the world each year [5]. It is estimated that the existing thalassaemia patient in Bangladesh is about 1 lac and the suspected total number of $\beta$-thalassaemia major and $\mathrm{Hb} \mathrm{E} \beta$ - thalassaemia of the new-born are around 1040 and 6443 per year respectively in the country [7]. The World Health report estimates that 3\% populations in Bangladesh are carrier of $\beta$-thalassaemia gene which means that there are 3.6 million carrier of beta thalassaemia gene in Bangladesh [8]. It is presumed that approximately six thousand thalassaemic children are born each year in Bangladesh [9]. The number of patients suffering from thalassaemia (beta major and HbE beta) with different levels of severity is estimated to be approximately 60,000 - 70,000 [10]. With the birth rate of 21.6/1000 in Bangladesh, it could be estimated that nearly 2500 thalassaemia major cases are added every year in Bangladesh [11].

The impacts of thalassaemia among children are physical, social and psychological [12], absenteeism from school, decreased academic achievement, reduced self-esteem and inadequacy in undertaking normal tasks, feeling anxious about uncertain and unknown situations, restrictions in social communication and playing, isolation and depression [13]. These issues negatively affect the quality of life of the patient [13]. Affected children face many stresses in their whole life, including frequent blood samplings for laboratory tests, multiple transfusions and frequent subcutaneous injections and oral therapy of iron chelator drugs [14], which altogether make the patient susceptible to psychiatric burden namely depression and anxiety [14]. In children, especially, $\beta$-thalassemia major and its complications carry a significant psychological impact, causing emotional burden, hopelessness, and difficulty with social integration [12]. Patients with thalassaemia suffer from a wide range of physical and psychological problems. 
Growth retardation delayed puberty and deformities since the disease change the patients' physical appearance and body image which consequently lead to a poor self-image and low self-steam [13] [15] [16]. The influences of thalassemia on physical wellness can lead to physical distortion, growth blocking, and postponed maturity [17]. Thalassaemic children have been described to show impaired abstract reasoning, deficits of language, attention, memory, constructional/visual-spatial skills and executive functions, all of which are more prominent in hemosiderotic subjects [18]. A study of [19] revealed that three superordinate themes which reflect the burden and stigma of living with thalassaemia (loss of normal childhood), mechanisms used to protect the self (minimizing differences) and the fragile process of self-reformulation. These findings highlighted the dynamic nature of children's experiences as they vacillate between feelings of being overwhelmed by their condition and self-reformulation using a variety of coping mechanisms [19]. The contribution of personal and contextual factors, such as deterioration of health, discrimination and experiences of medical care, can potentially disrupt coping efforts and influence the dynamic adaptational process [19]. The core category with transfusion dependent thalassaemia (TDT) of living experience includes illness understanding, a sense of difference, emotional experiences \& managing the differences. Children perceived themselves to be different from their peers due to having transfusion dependent thalassaemia (TDT) and unable to engage in strenuous activities, vulnerable to illnesses, different in appearance, altered body image, feelings of sadness, shame, envy, anger and worry [20]. They attempted to manage these differences in order to gain a sense of normalcy through preserving normal blood amount, decreasing body iron, strengthening experiences and mobilizing supports [20].

There are some studies such as impact of thalassaemia on quality of life, psychological problem in children with thalassaemia. In Bangladesh there are many thalassaemic patients. However a few information regarding in depth study is related to thalassaemic children. Therefore, it is urgent to describe the lived experience of the thalassaemic children. Findings from this study may provide information for the pediatric nurses to help for these types of children.

\subsection{Objective}

The purpose of this study was to describe the lived experience of thalassaemic children in Bangladesh

\section{Methods}

\subsection{Study Design}

A descriptive qualitative study was conducted to describe the Experience of Thalassaemic Children Qualitative research approach is appropriate when the researcher want to seek deep understanding of human problem. Individual in-depth interview is widely used by the health care researchers to describe the participants' experiences related to health [21]. 


\subsection{Study Participants}

The study participants were 20 children ranging from ages 13 to 18 . Purposive sampling technique was used. Children who had thalassaemia and were willing to express their experiences were selected from out patients department \& day cares unite of hematology department of Dhaka Medical College Hospital (DMCH) Dhaka. The DMCH is situated in the capital city of Bangladesh, enough number of study sample were available here who provide necessary information to find out the answer to the research questions of the study.

The inclusion criteria for selecting eligible subjects were:

1) Children who attending OPD and day care unit of hematology department for routine assessment.

2) Children with thalassaemia aged 13 - 18 years.

3) Free from any other chronic diseases.

The exclusion criteria are:

1) More than 18 years \& less than 13 years.

2) Having other chronic disease.

3) Who do not agree to give information.

\subsection{Instruments}

The questionnaire consists of two parts. The first part was consisted of 12 questions about socio-demographic characteristics such as: age, Gender, Religion, Education, Occupation of parents, Residence, Age at which thalassaemia was diagnosed, Family history of thalassaemia, Time Interval of blood transfusion, Blood group and Family income. The second part of the instrument was semi-structured individual interview guidelines developed by the researcher based on literature reviewed by the researcher. Validity of the interview guide was done by three experts (two experts from NIANER \& one from DMCH (Medical Doctor) and it was found representative. Guiding Questions of an in-depth interview of children with thalassaemia are as follows:

\section{Interview Guidelines}

\section{1) Introductory Question}

a) How far do you know about your illness?

2) Transition Question

a) Could you elaborate the problems you have faced or are going through presently in relation to thalassaemiahlassaemia?

\section{Key Questions}

a) Do you feel tired?

b) How do you see yourself as compared to others?

c) What are your feelings about adhering to the long term treatment?

d) Is thalassaemia disease has impact on your education?

e) How do you cope with the illness?

f) Do have any difficulty performing the work?

g) Are you satisfied with your body image? 
h) Do you discuss your illness and its related problems with your friends?

i) Do you have enough stigma to play all kinds of sports?

j) Have your sports activities become limited due to thalassaemia disease?

k) Do you feel different from your siblings?

1) Do you get the same attention from your parents?

$\mathrm{m})$ Do you feel that your disease is burden on your parents?

n) Does Thalassaemia affect your social life?

\subsection{Data Collection}

As researcher is the instrument of the qualitative study. Data was collected through semi-structured individual's interview guidelines developed by the researcher. The duration of interview was lasting between $60-70$ min and sampling was continued until data saturation, meaning that no new data code or data was obtained and all the conceptual levels were completed. The interviews location were selected by the participants and were mostly in thalassaemia unite of the outpatient department at hospital. Each interview was audio-recorded and transcribed verbatim. The final interview guide consisted of sixteen questions and additional questions were asked during the interview process, these questions were different for each participant and were based on the researcher's subjective judgment of pertinence. This study was approved by the Institutional Review Board (IRB), National Institute of Advanced Nursing Education and Research (IRB No.Exp.NIA-2018-26) and Banga Bandhu Sheikh Mujib Medical University (BSMMU). After getting permission from the Hospital Director and Nursing superintendent, researcher were went to haematology department \& there introduced with OPD Incharge \& taking permission from her/him. Then researcher was introduced with study children. Children were allowed to withdraw from the research process at any time. Before starting the interview, the purpose of the study was explained to the children as well as their parents and the children were assured about the confidentiality of their information by assigning each of them a number. After determining the location of the interview, the researchers obtained childrens' permission to record their interviews. Data was collected up to data saturation by face to face interview. Interviews were recorded with a voice recorder with the consent of the children and their parents. After obtaining signed informs consent from the children and parent's, interviews were carried out using a conversational method. Obtained information was hand written by researcher and audio voice recording was done which was later translated into verbatim by researcher.

\subsection{Data Analysis}

Data were analyzed using the process of content analysis. All the interviews were immediately transcribed verbatim. The transcripts were read by the authors several times to get insight into the participants' experiences. Descriptive statistics frequency, percentage, mean median and standard deviation were used to ana- 
lyse the participants' demographic characteristics. The researcher coded the data, coding is the marking sections of data towards the development of categories. Coding starts from participants' words which prevent researchers from imposing their own framework and ideas on the data [22], then coding was cluster into categories.

\section{Results}

A descriptive qualitative research approach was used to describe the lived experience of thalassaemic children at outpatient department and day care unit of hematology department in the Dhaka Medical college hospital. Participants of the study comprised of 20 children recruited purposively. The findings of the present study are presented as follows:

\subsection{Socio-Demographic Characteristics of Thalassaemic Children}

This chapter presents findings of the study collected from in depth interviews of children with thalassaemia from 13 to 18 years of age participated in the study who have diagnosed thalassaemia and undergone treatment. The results of the study are presented as description of children characteristics (Table 1).

Table 1 showed that the demographic characteristic of thalassaemic children's mean age was $16.05 \pm 1.877$. The majority of the gender was male (12) $60 \%$ and female (8) $40 \%$. Most of the children were Muslim (19) $95 \%$. The majority of the children's mothers' occupations were housewife (18) $90 \%$ and fathers' occupations were service holder (8) 40\% and business (8)40\%. About (14) $70 \%$ children's educational level was school level that means (P.S.C, J.S.C, and S.S.C). (11) $55 \%$ children live in pacca house that means building. Age of diagnosed thalassaemia (in a month) the mean age were $88.03 \pm 66.334$. About (6) $30 \%$ father (5) $25 \%$ sister and (3) 15\% mother have thalassaemia. Time interval of Blood Transfusion (in month) the mean time was $3.15 \pm 1.981$. Children's blood group were $B+$ ve $45 \%, A+$ ve $25 \%$ and $A B+$ ve $25 \%$.

\subsection{Experience of the Thalassemic Children}

This study revealed four major themes that have been derived from participant's experience. These themes included 1) Understanding of Children Meaning of Thalassaemia 2) Feeling Frustrated Experience and Disease Management 3) Family Relationship: 4) Social Interactions and eleven subthemes were identified based on the experience of thalassemic childrens'. Understanding of Children's Meaning of Thalassaemia included three sub themes: a) perception of children, b) unable to perform daily activities and c) educational impact. Feeling Frustrated Experience and Disease Management consisted of three sub themes: a) feelings about long term treatment, b) coping and c) altered body image. Family Relationship consisted of three sub themes: a) differences from siblings b) parental attention and c) feeling burden. Social Interactions included two sub themes: a) sharing with peer b) inability to social interaction. 
Table 1. Demographic Characteristics of Thalassaemic Children

\begin{tabular}{lrccc}
\hline \multicolumn{1}{c}{ Variables } & Category & $\mathrm{N}$ & $\%$ & $\mathrm{M} \pm \mathrm{SD}$ \\
\hline Age & & & & $16.05 \pm 1.877$ \\
Gender & & & & \\
& Male & 12 & 60.0 & \\
& Female & 8 & 40.0 &
\end{tabular}

Religion

$\begin{array}{lcc}\text { Muslim } & 19 & 95.0 \\ \text { Non-Muslim } & 1 & 5.0\end{array}$

Mother's occupation

$\begin{array}{lcc}\text { Housewife } & 18 & 90.0 \\ \text { Service holder } & 2 & 10.0\end{array}$

Father's occupation

$\begin{array}{lll}\text { Service holder } & 8 & 40.0 \\ \text { Business } & 8 & 40.0 \\ \text { Others } & 4 & 20.0\end{array}$

Educational level

$\begin{array}{lcc}\text { No schooling } & 3 & 15.0 \\ \text { School } & 14 & 70.0 \\ \text { College } & 3 & 15.5\end{array}$

Residence

$\begin{array}{ccc}\text { Pacca } & 11 & 55.0 \\ \text { Kacha } & 9 & 45.0\end{array}$

Age of disease diagnosed (in month)

$88.03 \pm 66.334$

$\begin{array}{llll} & \text { Father } & 6 & 30.0 \\ & \text { Mother } & 3 & 15.0 \\ \text { Family history of } & \text { Sister } & 5 & 25.0 \\ \text { thalassaemia } & \text { Grandparent } & 2 & 10.0 \\ & \text { Not know } & 6 & 30.0\end{array}$

Monthly family income (in Taka/month)

Time interval of blood transfusion (in month)

$3.15 \pm 1.981$

\begin{tabular}{llll} 
& A + ve & 5 & 25.0 \\
Blood Group & B + ve & 9 & 45.0 \\
& AB + ve & 5 & 25.0 \\
& O + ve & 1 & 5.0 \\
\hline
\end{tabular}


Theme 1. Understanding of Children Meaning of Thalassaemia

Thalassaemic children came to understand their illness through their experiences of everyday life. This theme consisted of three sub themes.

a) Perception of Children

Most of the thalassemic children reported about their illness that thalassemia is a Genetic/hereditary disease. They feel different types of problem due to this disease. They can't eat properly, can't play, can't study regularly and want to stay in bed. When their Haemoglobin level decreases they feel tired, weak, feel headache, they take blood and medicine regularly. One child reported: "I know that it is a hereditary disease. For this disease blood must be taken in every month. Someone took it after 1 month and someone took it after every 2 months and someone took it after a long time" (Child 11)

Another one stated: "I try to know about it on my own. I don't know what I should say about it. It is a painful disease. There is nothing else. I will live with it of my whole life. I know about it that it never be cured fully. It's just a painful disease like cancer. I do not feel bad about me. It does not hurt me" (Child 13).

Another child noticed: "I feel fever at night. It stays for a long time, I feel pain in my hands and legs. Everything in the near future can be destroyed without proper treatment such as the liver function can be destroyed, heart can be blocked. If I get married then it will be difficult to take baby or I can't take" (Child 15).

\section{b) Unable to perform daily activities}

The majority of the children expressed that they have difficulty performing the work. They feel tired to do work, can't do heavy work. When they walk they feel weak. They feel pain in hands and legs. They cannot do all regular activities by themselves. That's why they feel the need to help. One child stated: "I often get sick. I cannot do all my work by myself. I need help now" (Child 8).

Another child reported: "I have faced many problems in my work, I work in a courier service, one month I feel good and one month I feel ill. For this reason, often I take a vacation, I am not healthy, and how do I work? (Child 16).

\section{c) Educational Impact}

Most of the children described their educational experienced, they expressed that thalassaemia disease has an impact on their education. Due to this disease, they can't study properly, can't attend school regularly, and can't remember their lesson. When they have blood, they read well, attend in class every day. When blood is reduced they can't do these. One child reported:

"This disease has a major impact on my education, when I entered class five, after two months my disease was detected, and then I was admitted to Dhaka Medical College Hospital for six months. After six months I gave the exam and I got A+. But my education has finished for this disease. I had merit and confidence but now there is nothing. I had a lot of hope to do study, but my friends are now studying in Dhaka. If I see them I think, if I had no illness, I could have studied like them" (Child 16).

Another child reported: "Yes, this disease is affecting my study. I cannot give 
the exam for the operation I cannot go to school. I became late for a year. I cannot do the study properly. The results of the test are fair. I do not go to school when I became sick' (Child 9).

Theme 2. Feeling Frustrated Experience and Disease Management

a) Feelings about Long Term Treatment

Most of the thalassemic children recognized their feelings about adhering to the long term treatment that it is very expensive, costly, and treated for whole life, blood and medicine must be taken. They also expressed that they feel tired when they went to play the game, walk on stairs and do any work. Although they feel tired to go to school, walk a little quickly or do any heavy work.

One child reported: "It is not possible for everyone to treat long-term care, because it is so expensive. Such as my home is too far. It is so difficult for us. My father is no more. My mother manages the money for our two sisters for treatment.it is very difficult for her to manage money every month" (Child 10).

Another child stated: " $P$ ve never had permanent treatment for this disease. As long as the disease is being diagnosed from the childhood I have taken blood and medicine. It is an expensive treatment. There is no guarantee of how long it will be to take medication, and it will continue to depend on medicines. All the things we should buy. Hospital doesn't give any medicine. The medicine that I have taken is so costly all from aboard. A lot of money will cost for the medicine if it would be taken for whole life. Besides, it doesn't get from near to the house. It should be taken from Dhaka or from Mymensingh" (Child 8).

Another child stated: "I feel tired if I do any work. If I feel tired then I stop my work. I take rest by sitting. And if I feel better then I start my work again. I can't do heavy work. I can't take a load on my head. I cannot pick up more than $5 \mathrm{~kg}$ ' (Child 7).

\section{b) Altered Body Image}

On the other hand, body image changes were a major experience for children. Almost all (above ninety percent) thalassemic children stated that they didn't satisfy with their body image associate with thalassaemia. In comparing to others, most of the thalassaemic children's feeling is that they see them-self different from others. They also expressed, when they think deeply, they feel that, they may get stronger with their growth they might be strong or better, but they didn't try to think it. One child reported: " $P m$ not satisfied with my physical condition. I should have been better. I cannot be better Because of this disease I cannot be good" (Child 4).

Another child stated: " $\mathrm{m}$ not concerned about my physical condition. God gives it, nothing has been done. But I could have been better off. I could have been like others if I did not have the disease" (Child 8). "I feel different from others because I am sick and they are healthy. Sometimes it feels so sad" (Child 9).

\section{c) Coping}

The majority of thalassemic children reported that they can cope with the ill- 
ness. When they become sick, they take medicines and blood, consulted with doctor, eat properly, drink water. One child reported: "When I got sick, I have to eat properly. I must be maintained the routine. If I follow the routine I became a little fit. I can do everything properly. When the blood is reduced, I face some problems in my work' (Child 1).

Theme 3. Family Relationship

a) Differences from Siblings

The thalassaemic children perceived themselves as different from their siblings. Most of the children stated they feel different from their siblings because of this disease. Few children stated that they didn't feel different from their siblings. One child reported: "I feel myself different from my other siblings. Because they are healthy I am ill. They can do all kinds of work. But I cannot. They can take care of themselves. They do not feel weak but I feel weak' (Child 17).

Another child stated: "I do not feel different myself from my other siblings. I can move like them. I can play like them" (Child 20).

\section{b) Parental Attention}

The majority of children reported that they get the same attention from their parents. They also reported sometimes they get more attention because of their illness. Few children said that their parents sometimes disturbed them. One child stated: "All children are equal to parents. Because of the illness, many times parents are more likely to me and sometimes they are often disturbed because they have to go to the hospital, have to spend money, and often say that this child is so sick and it cannot read or work like a healthy person and everyone else. It cannot live a normal life" (Child 8).

Another child noticed: "My parents take care of my brothers and sisters in the same way as they gave me the same attention" (Child 20).

\section{c) Feeling burden}

Thalassemic children reported that their disease is a burden on their parents. Most of the children complained that financial cost is associated with thalassaemia and its treatment. This includes the cost of medicine, investigation; blood transfusions and frequent hospital follow-up visit. One child reported: "Yes, of course, I understand that everything goes waste for me. The family has been harmed. If I do not get sick the family can be going well. My parents spend all of money for me which they earn. The family is going on" (Child 8).

Another child reported: "My disease seems to be a burden on my parents. They have to run in the hospital for me. Money is spending for me" (Child 9).

\section{Theme 4. Social Interactions}

\section{a) Sharing with Peer}

Most of the thalassemic children stated that they didn't discuss their illness and its related problems with their friends. Some children stated they discuss it with others.

One child stated: "I do not discuss it with my friends. When they talk about it I avoid them. I feel normal. I try to understand others that I am like you" (Child 
13)

Another one noticed: "I share my illness with my friends, family members. I said them to pray for me and if someone is known with them, then tell them to give me blood. In this way they can help me with blood" (Child 1).

\section{b) Inability to Socially Interactions}

Regarding sports activities most of the thalassemic children stated that they have enough stigma to play all kinds of sports, their sports activities become limited due to thalassaemia. They also noticed that they do not play all kinds of sports. When they try to play they feel tired, fall behind than others, and feel shy and uneasy. One child noticed: "I wanted to do all kinds of sports but I could not. That's why I was away from sports on my own" (Child 13).

Another child stated: "Due to illness, my sports have been limited. Everyone told me why did not I play? I said that I do not like it. I know that if I play the game, then I will become tired. I will be tired and feel uneasy, so I do not go to play" (Child 12).

Most of the children said that their social life is not affected by thalassaemia, because everybody shows them sympathy, their neighbor love them. Few children expressed that thalassaemia affected their social life. They feel many people at this age do many things. But they cannot do anything good for Society. One child reported: "It does not affect my social life. It will not because this is my disease and I am not seriously ill' (Child 15).

Another child noticed: "After an attack by the thalassemia, it affects my social life. Such as before I used to go to many places and took part in many works but now I cannot" (Child 1).

\section{Discussion}

The aim of this study was to describe the lived experience of thalassaemic children in Bangladesh. The study employed a qualitative research approach to better illuminate the child experience. The findings of the study revealed that thalassaemia has a substantial effect on physical, emotional, educational, financial and social life of children. Children's perceived that thalassaemia is a serious and distressing disease that required lifelong treatment and blood transfusion. Children extensively discussed their different areas of life associated with thalassaemia. Table 1 showed the demographic characteristics of thalassaemic children: Most of the children in the current study are muslin and male, their mean age was $16.05 \pm 1.877$. Majority percent of children study at school level. Most of the Children's blood group was B + ve and their disease diagnosed of mean age in a month were $88.03 \pm 66.334$.

\subsection{Understanding of Children Meaning of Thalassaemia}

In present study, children perceived themselves as different from healthy children. Their differences were explained according to their understanding of their illness. Thalassaemic children came to understand their illness through their ex- 
perience of everyday life. They noticed that they became very tired or unable to tolerate strenuous activities. They can't perform their regular activities such as school performance; play all kinds of game and other personal activities. Our findings were consistent with results of studies conducted by [23] [24]. When their Haemoglobin level decreased they feel tired, weak, sleepy, pain different parts of the body and eye and body become yellow like jaundice. Every $1-2$ months they went to hospital for regular visit and received blood and different types of medicine. They understood that thalassaemia is a genetic disease and it is not curable but treatable. Long-term treatment is required for this disease. It is not possible for everyone because this treatment is so expensive, lifelong and blood collection is very difficult for them. Financial issue is another burden of thalassaemia. It increased expenses of associated with transportation costs, treatment costs and blood transfusion costs. Previous studies have found similar findings [25] [26]. They also noticed that thalassaemia harmed their education. For this disease, they cannot perform their regular school activities. Most of the time, they were sick as a result they could not attend their exam. Children understood that they lost their memory gradually and they could not remember their lesson. Previous studies have shown that poor academic level was related to absence from school [15] [25] [27]. In addition, a study conducted by [25] revealed that parents considered thalassaemia as a factor that makes their children slow learners. Thus it is vital to assess if thalassaemia itself causes any learning difficulties among children, consequently need to establish appropriate interventions for educational programs.

\subsection{Feeling Frustrated Experience and Disease Management}

Thalassemic children expressed about long term treatment. Long term treatment is to be treated as long as they live. It is so expensive, medicine is very costly. Every day medicine must be taken and after $1 / 2$ months interval blood should be taken. They manage their illness by taking medicine, blood transfusion, proper eating, rest, blood test and regular follow up visits. They feel tired when they perform work, school activity and playing games. They feel more tired when they do heavy work and walk quickly. Previous studies have found similar findings [24]. Altered body image presented the thalassaemic children's perception of their appearance. They experienced different in their general appearance changes, which were observable to others. The children were dissatisfied with their appearance including, unhealthy, illness and body structure. This finding was consistent with previous study [28]. Physical changes in thalassaemic children were another issue that has great impact on their satisfaction. Children expressed their dissatisfaction about their body image. This findings similar to the previous studies have shown that physical changes associated with thalassaemia have led to feeling of oddness, low self-esteem and feeling insufficiency among thalassaemic children [25] [27] [29]. Therefore, it is indeed imperative to explore the impact of physical changes on thalassaemic children and how do they perce- 
ive their body image. The children perceived themselves as different from other, especially peers. Their differences were explained according to their emotional experienced of this disease.

\subsection{Family Relationship}

Findings of present study relationship of thalassaemic childrens' with their siblings, parents and other family members are well, but some differences are seen. Children noticed that they feel themselves different from their siblings because their siblings are healthy, they can do all kinds of work can play, can take care of themselves but sick children can't do these. Previous studies, the results of which were consistent with this study, showed that physical changes resulting from the disease lead to feelings of being different [30]. In this study the relationship of the children with their siblings was not generally adversely affected although they felt different from their siblings as also documented by others. This was consistent with previous studies [31]. Children also noticed that they get same attention from their parents as their siblings get these. Sometimes they get more attention from their parents because their illness. Same findings were found by [32]. But often their parents are disturbed for them. Because they have to go to hospital, spend money and often said that the child is so sick it cannot read or work properly, like a healthy child and everyone can do that. Genetic hemoglobin disorders like thalassaemia increase the burden of parental problems because they impose disabilities for children in the future. Some children said that their disease is harming on their parents. Because the treatment of this disease is very much costly, their parents spend a lot of money for their treatment. Some children view that financial burden was the important on their parents. Previous authors have found similar findings [24]. In a qualitative study on children with thalassaemia in Pakistan, high volume of family's problems have been reported and the researchers believe that some families cannot afford the cost of transporting the child to the hospital for routine treatment procedures [19].

\subsection{Social Interactions}

The findings of the present study showed that all children believed that disease has importantly affected on their life. Children felt that thalassemia affects their social life because they can't do any good work for society. Their friends do not want to mix with them. They can't move and join with their friends in social activities. Previous studies have found similar findings [24] [28]. Children with thalassaemia were shown to have significantly higher rate of social dysfunction than their unaffected siblings. Another result of the study, thalassaemia disease is a serious health disorder, which is associated with physical, financial and social problems. These problems not only reduce the life expectancy of children but also deprive their enjoyable life. Therefore, they need health and social support systems which can give them hope in their lives. Children noticed that they share with friend about their illness and said them to give blood for them. In this way 
their friends can help them with blood. Children stated about their sports activities. Before, they could play all kinds of games but now they can't play all kinds of games due to their sickness. They know that if they play games they will become tired and feel uneasy and shame, so they do not go to play. They wanted to do all kinds of sports but they could not. That's why they were away from sports by themselves. In the study by [33] the parents had experienced about their children and stated that their children's have tiredness in recreational activities. This was consistent with present study

The study had some limitations. First, the researcher used qualitative research approach and recruited the sample using purposive sampling, only one setting. Therefore, the credibility of the study results could not be generalized with all of the children in Bangladesh.

\section{Conclusion and Recommendations}

\subsection{Conclusion}

The findings of this study identified four main themes that involved living experience with thalassaemia of children. This study indicated that thalassaemia has affected negatively several areas of health of these children including physical, emotional, social financial and educational areas. To reduce these problems, it requires comprehensive constant support and surveying health and medical status of these children to promote care and decrease the suffering of thalassaemic children. The finding may provide information for the pediatric nurses, which will help in decreasing the sufferings and morbidity of the children with thalassemia.

\subsection{Recommendations}

The rapidly growing numbers of children diagnosed with thalassaemia in Bangladesh clearly indicate that thalassaemia will be an emerging health burden in our country. The researcher strongly recommended that thalassaemia can be prevented by comprehensive national integrated prevention programs which include public awareness and education, carrier screening, genetic counseling, premarital screening and prenatal diagnosis. Therefore, generalizability of the study results further research should be recommended in a variety of settings with a larger sample size.

\section{Acknowledgements}

First of all, thanks to Allah for giving me the strength to complete this thesis. And then praise to Professor Chung Yul Lee, former director of NIANER, Mugda, Dhaka. This project has been accomplished through the encouragement, guidance and support of many special persons. My biggest thanks and gratitude goes to my Chief advisor Dr. Shanzida Khatun for her constructive guidance and warm love throughout the research process. I am very much grateful to all validators and translators to develop my instruments. This project would not have 
been possible without enthusiasm and co-operation. Special thanks to my daughter (Adri) who always support me for this research.

\section{Conflicts of Interest}

The authors declare no conflicts of interest regarding the publication of this paper.

\section{References}

[1] Ryan, K., Bain, B.J., Worthington, D., James, J., Plews, D., Mason, A., Roper, D., Rees, D.C., De La Salle, B., Streetly, A. and British Committee for Standards in Haematology (2010) Significant Haemoglobinopathies: Guidelines for Screening and Diagnosis. British Journal of Haematolgy, 149, 35-49. https://doi.org/10.1111/j.1365-2141.2009.08054.x

[2] Saha, R., Misra, R. and Saha, I. (2016) School Functioning Activity of Bengali Thalassemic Children Attending a Tertiary Care Hospital of Eastern India. International Journal of Travel Medicine and Global Health, 4, 82-87. https://doi.org/10.21859/ijtmgh-040303

[3] Baghianimoghadam, M.H., Sharifirad, G., Rahaei, Z., Baghianimoghadam, B. and Heshmati, H. (2011) Health Related Quality of Life in Children with Thalassemia Assessed Based on SF-20 Questionnaire in Yazd, Iran: A Case-Control Study. Central European Journal of Public Health, 19, 165-169.

https://doi.org/10.21101/cejph.a3640

[4] World Health Organization (2008) Management of Haemoglobin Disorders: Report of a Joint WHO-TIF Meeting. World Health Organization, Geneva.

[5] Cheuk, D.K.L., Mok, A.S.P., Lee, A.C.W., Chiang, A.K.S., Ha, S.Y., Lau, Y.L. and Chan, G.C.F. (2008) Quality of Life in Patients with Transfusion Dependent Thalassemia after Hematopoietic SCT. Bone Marrow Transplantation, 42, 319-327. https://doi.org/10.1038/bmt.2008.165

[6] Galanello, R. and Origa, R. (2010) Beta-Thalassemia. Orphanet Journal of Rare Diseases, 5, Article No. 11. https://doi.org/10.1186/1750-1172-5-11

[7] Khan, W.A., Banu, B., Amin, S.K., Selimuzzaman, M., Rahman, M., Hossain, B. and Razzaque, M.A. (2005) Prevalence of Beta Thalassemia Trait and Hb E Trait in Bangladeshi School Children and Health Burden of Thalassemia in Our Population. DS (Child) Journal of Health, 21, 1-7.

[8] Salsabil, M.A., Islam, M., Jahan, D. and Khan, M.A. (2014) Inherited Haemoglobin Disorders among Apparently Healthy Individuals-An Analysis of 105 Cases. Journal of Armed Forces Medical College, Bangladesh, 10, 90-94. https://doi.org/10.3329/jafmc.v10i2.26198

[9] Rahman, M.J. and Rahman, M.H. (2003) Prevention \& Control Strategy of Thalassemia in Bangladesh. The Orion Medical Journal, 16, 121-122.

[10] Weatherall, D.J. (2010) The Inherited Diseases of Hemoglobin Are an Emerging Global Health Burden. Blood, 115, 4331-4336.

[11] Mandal, P.K., Maji, S.K. and Dolai, T.K. (2014) Present Scenario of Hemoglobinopathies in West Bengal, India: An analysis of a Large Population. International Journal of Medicine and Public Health, 4, 496-499. https://doi.org/10.4103/2230-8598.144127

[12] Mazzone, L., Battaglia, L., Andreozzi, F., Romeo, M.A. and Mazzone, D. (2009) Emo- 
tional Impact in $\beta$-Thalassaemia Major Children Following Cognitive-Behavioural Family Therapy and Quality of Life of Caregiving Mothers. Clinical Practice and Epidemiology in Mental Health, 5, Article No. 5. https://doi.org/10.1186/1745-0179-5-5

[13] Thavorncharoensap, M., Torcharus, K., Nuchprayoon, I., Riewpaiboon, A., Indaratna, K. and Ubol, B.O. (2010) Factors Affecting Health-Related Quality of Life in Thai Children with Thalassemia. BMC Hematology, 10, Article No. 1. https://doi.org/10.1186/1471-2326-10-1

[14] Pattanashetti, M., Mugali, J., Pattanashetty, N. and Patil, S. (2017) A Study of Severity of Depression in Thalassemia Patients. The International Journal of Indian Psychology, 4, Article No. 85.

[15] Ismail, A., Campbell, M.J., Ibrahim, H.M. and Jones, G.L. (2006) Health Related Quality of Life in Malaysian Children with Thalassaemia. Health and Quality of life Outcomes, 4, Article No. 39. https://doi.org/10.1186/1477-7525-4-39

[16] Telfer, P., Constantinidou, G., Andreou, P., Christou, S., Modell, B. and Angastiniotis, M. (2005) Quality of Life in Thalassemia. Annals of the New York Academy of sciences, 1054, 273-282. https://doi.org/10.1196/annals.1345.035

[17] Shaligram, D., Girimaji, S.C. and Chaturvedi, S.K. (2007) Psychological Problems and Quality of Life in Children with Thalassemia. The Indian Journal of Pediatrics, 74, 727-730. https://doi.org/10.1007/s12098-007-0127-6

[18] Monastero, R., Monastero, G., Ciaccio, C., Padovani, A. and Camarda, R. (2000) Cognitive Deficits in Beta-Thalassemia Major. Acta Neurologica Scandinavica, 102, 162-168. https://doi.org/10.1034/j.1600-0404.2000.102003162.x

[19] Mufti, G.E.R., Towell, T. and Cartwright, T. (2015) Pakistani Children's Experiences of Growing up with Beta-Thalassemia Major. Qualitative Health Research, 25, 386-396. https://doi.org/10.1177/1049732314552663

[20] Yunak, R., Chontawan, R., Sripichayakan, K., Klunklin, A. and Jordan, P. (2009) Living with the Differences: Thai Adolescents' Experiences of Living with Transfusion-dependent Thalassemia. Pacific Rim International Journal of Nursing Research, 13, 318-331.

[21] DiCicco-Bloom, B. and Crabtree, B.F. (2006) The Qualitative Research Interview. Medical Education, 40, 314-321. https://doi.org/10.1111/j.1365-2929.2006.02418.x

[22] Quick, J. and Hall, S. (2015) Part Two: Qualitative Research. Journal of Perioperative Practice, 25, 129-133. https://doi.org/10.1177/1750458915025007-803

[23] Aljeesh, Y.I. (2016) Quality of Life among Thalassemia Children Patients in the Gaza Strip. American Journal of Nursing Science, 5, 106-113.

https://doi.org/10.11648/j.ajns.20160503.15

[24] Shahraki-vahed, A., Firouzkouhi, M., Abdollahimohammad, A. and Ghalgaie, J. (2017) Lived Experiences of Iranian Parents of Beta-Thalassemia Children. Journal of Multidisciplinary Healthcare, 10, 243-251.

https://doi.org/10.2147/JMDH.S132848

[25] Wahab, I.A., Naznin, M., Nora, M.Z., Suzanah, A.R., Zulaiho, M., Faszrul, A.R. and Kamaruzaman, W.S. (2011) Thalassaemia: A Study on the Perceptionof Patients and Family Members. Medical Journal of Malaysia, 66, 326-334.

[26] Prasomsuk, S., Jetsrisuparp, A., Ratanasiri, T. and Ratanasiri, A. (2007) Lived Experiences of Mothers Caring for Children with Thalassemia Major in Thailand. Journal for Specialists in Pediatric Nursing, 12, 13-23. https://doi.org/10.1111/j.1744-6155.2007.00085.x 
[27] Yahia, S., El-Hadidy, M.A., El-Gilany, A.H., Anwar, R., Darwish, A. and Mansour, A.K. (2013) Predictors of Anxiety and Depression in Egyptian Thalassemic Patients: A Single Center Study. International Journal of Hematology, 97, 604-609. https://doi.org/10.1007/s12185-013-1322-Z

[28] Roy, T. and Chatterjee, S.C. (2007) The Experiences of Adolescents with Thalassemia in West Bengal, India. Qualitative Health Research, 17, 85-93.

[29] Messina, G., Colombo, E., Cassinerio, E., Ferri, F., Curti, R., Altamura, C. and Cappellini, MD. (2008) Psychosocial Aspects and Psychiatric Disorders in Young Adult with Major. Internal and Emergency Medicine, 3, Article No. 339.

https://doi.org/10.1007/s11739-008-0166-7

[30] Pouraboli, B., Abedi, H.A., Abbaszadeh, A. and Kazemi, M. (2014) Living in a Misty Marsh: A Qualitative Study on the Experiences of Self-Care Suffering of Patients with Thalassemia. Iranian Journal of Nursing and Midwifery Research, 19, 77-82.

[31] Shosha, G.M. (2014) Needs and Concerns of Jordanian Mothers with Thalassemic Children: A Qualitative Study. The Journal of American Science, 10, 11-16.

[32] Alzahrani, R.A., Almutairi, O.M., Alghoraibi, M.S., Alabdulwahed, M.S., Abaalkhail, M.K. and Alosaimy, M.T. (2017) Quality of Life in Transfusion Dependent Thalassaemia Patients. Journal of Taibah University Medical Science, 12, 465-470. https://doi.org/10.1016/j.jtumed.2017.05.006

[33] Arbabisarjou, A., Karimzaei, T. and Jamalzaei, A. (2015) The Perception of Biological Experience in Patients with Major Thalassaemia: Aqualitative Research. Global Journal of Health Science, 7, 79-87. https://doi.org/10.5539/gjhs.v7n1p79 